\title{
A MACRO-ECONOMIC APPROACH TO RISK MANAGEMENT ${ }^{1}$
}

\author{
by Orio Giarini ${ }^{2}$
}

\section{Economic history and economic theory}

The first industrial revolution started around 1750. The flying shuttle weaving machine and the steam engine, combined, are the symbol of the new industrial mode of production. Increasing use of technology, greater and greater need for capital, concentration of production and increasing productivity of labor, are the main interdependent features of this new era.

The production mechanisms and the organization of the economy slowly but inexorably leave behind the old agriculturally based society and head for the new frontiers of industrialization. In 1776 - just 200 years ago - Adam Smith published his famous book on the "Wealth of Nations", playing the role of the Christopher Columbus of the new world of economic knowledge. Ricardo is then only four years old, whereas Malthus is ten. John Stuart Mill will be born only 30 years later : he will publish his "Principles of Political Economy" in 1848, in the same year as Marx's Manifesto, but still 19 years before the publication of "The Capital".

Clearly, economics is the offspring of this period of economic history, dominated by the development of the industrial mode of production.

Until the second half of the XIXth century, new but non-science-based technology stimulates economic growth ${ }^{3}$ : the phenomenon is impressive because it is cumulative, and short-term cycles appear more and more to be a mere "noise" in the general upward trend, instead of inevitable recessions pushing society back to the starting point. Still the average rate of growth, although not measured or measurable by modern accounting techniques, is not higher than 2 or 3 per cent per year.

And while economic theory, interpreting current experience (Ricardo himself was a practical business man) focuses its interest on the industrial mode of production, it is also very much concerned with a "steady state equilibrium".

Only at the end of the last century does technology begin to use scientific knowledge for innovation and very few people indeed are aware of this new phenomenon (and in any case no major economist and no major scientist). Genève.

1 Paper presented at the KSD Symposium at Queen's College, Oxford, April 5, 1976.

2 Economiste, chargé d'enseignement à l'Institut Universitaire d'Etudes Européennes,

3 See David S. Landes "Technological Change and Industrial Development in Western Europe from 1750 to the present", Cambridge University Press 1972. 
It will take many decades for the full results of such a marriage to mature into the unprecedented economic growth that has taken place since the second world war - unique performance on such a scale.

Science-based technology made us live, in the advanced countries, about a quarter of a century after second world war, something like the story of Alice in Economic Wonderland. A material dream came true, or almost true.

Economists have learned in the last 20 years not to speak of a steady state economy, but a steady growth. Whereas, as late as 1939, Roy Harrod did not think it necessary to consider technological progress in his model, while Alvin Hansen was writing at the same time that technology was diminishing the need for capital and would ultimately provoke a decrease in wealth, nobody has fought as much as the economists in the last three years against the idea that the real rate of growth will come down soon or later. Faith in science and technology has finally trapped them too.

Furthermore, economic theory is still consistently conditioned by its origin in the industrial mode of production.

Let us now put a very naive question: are the so-called advanced industrial countries living in an economic environment where the industrial mode of production is dominant or is at least growing proportionally more than any other economic activity? The answer is clear-cut: NO.

Given that it is common today for the pure cost of producing an article to represent about $20 \%$ of the final price (in some cases even $10 \%$ ), and that the rest is absorbed by such functions as storage, distribution, marketing, safety operations, etc., the definition of our society as post-industrial becomes reasonably adequate.

Aren't we maybe looking at economic phenomena with out-of-date glasses, accepting the underlying assumption that the economic system is essentially a production system?

\section{The diminishing returns of technology}

The paradox about the effects of science and technology on the economic structure is that their success has reduced their importance in the production system. Everybody is impressed by the productivity gains due to technology in the last two centuries: higher rates of production, concentration and the growing size of production-units have all contributed to it.

But the chemical engineer has already started to observe, over the past ten years, that the productivity gains achieved by raising the output of an ammonia or ethylene plant from 1,000 to 2,000 tons per day are questionable, and more questionable if it is raised to 3,000 or more. Technically it is feasible.

One can reasonably expect a diminishing cost per unit of product, but this productivity is more than offset by the cost of storage, and feeding raw materials, the storage of the finished product, the cost of maintenance, the cost of major accidents, etc.

Productivity accounting can be trickly : one can calculate the gains in productivity at every specialized production and distribution stage, but the final sum of those productivities may be a net loss in total productivity. 
Take the extreme case of liquid fertilizers in the United States. It is a good idea to use liquid ammonia as a direct fertilizer : one does not need to transform it into a solid product. The trouble starts with the fact that one has to store it in a controlled temperature and/or pressure vessel, otherwise it evaporates. Then (using special machines) the product is injected into the soil during the period of three weeks in a year, $50 \%$ of it in three days. The rest of the year one has to pay storage costs (the production is continuous, and cannot be switched on and off) and distribution cost, and it is here that excessive concentration of production becomes a real burden (several hundred thousand tons per year are involved).

Furthermore, the whole production and distribution system becomes more vulnerable due to bottle-necks, accidents, arson of any kind, not to speak of pollution.

Net, real productivity gains are therefore something much more complex than is suggested by a simple look at the economic machine as if it were essentially a production machine. But, after all, it seems reasonable that the economy should yield more net material welfare.

In these preceding remarks, we have maybe one of the possible explanations of the general trend towards slower economic growth.

They may also help in interpreting the fact that in the last 20 years, in almost all the industrialized countries, the rate of industrial damage paid for by insurers has grown at a speed which is constantly higher than the growth of national income. Even making some allowance for the verification of Engel's law, the phenomenon of the diminishing returns of technology seems to be present in its own right ${ }^{4}$. From the point of view of the industrial revolution, technology is not only the source of the greatest historical achievement in economic growth, but is now also the source of two increasing phenomena which are leading us away from a production-dominated economic system.

a) the phenomenon of tertiarization;

b) the phenomenon of the increasing vulnerability of the economic system.

It is obvious that technology can and does do much to increase the productivity of the tertiary sector of the economy, but here we have also to consider the fact that soft-ware technology or even social technology seem to be more important than simple hard-ware technology. In other words, the "how to use it" and the "why to use it" of a new technological breakthrough is becoming more important than ever, as compared with the "just use it" of the golden era when the yields of hard-ware technology were highest.

The link between these macro-economic phenomena and the development of risk management in industry and, generally in society, seems evident.

4 See "Economics, Technology and Vulnerability", lettre d'information N. 19, Geneva Association, March 1975. 


\section{Risk Management in the post-industrial society}

In practice, Risk Management has some clear connotations :

a) the increased vulnerability of the economic system is making it steadily clearer that more and more risks other than the traditional entrepreneurial risks (the existence and conquest of a market) are becoming an essential feature of any policy of controlling and managing or at least coordinating the activity of the firm;

b) excessive specialization of functions and skills has increased the number of cases where productivity accounting shows a schizophrenic lack of integration and even of reciprocal information. Specialized expertise has produced too much lateral blindness. Too many cases of expected productivity have resulted in too many losses due to "outside" influences.

Risk management involves reconstructing a puzzle: it involves reinforcing the strategic capability of a firm.

Getting back to our general economic principles, we can see then that what is at stake is the new definition of risk and uncertainty.

Traditionally, Schumpeter and Knight limited their view to the entrepreneurial risk, seen essentially as a market risk. Insurable risk is seen as a simple production cost : one gets a policy to have some type of product guaranteed just as one buys a more expensive machine. This picture is obviously today far too simplified : risk is more and more complex and it is less and less obvious or even legitimate to distinguish between an entrepreneurial and a pure or insurable risk (not to count the theoretically insurable, but technically uninsurable risks).

\section{The need for some revision of economic theory}

Economics has been having a hard time these last few years to provide a general framework for action in face of the economic crisis. This is a pity not only for economists, but also for any type of people engaged in a responsible economic activity, who have to find somewhere reference points in order to know how and where they are heading.

We suggest here that maybe new light can be shed, through closer analysis of technological returns and of the phenomenon of tertiarisation of the economy (which is particularly evident within the secondary or industrial sector).

The tertiary or service activities suffer from a lack of interest on the part of economic theory which we can partially explain by the fact that economics has developed mainly out of the industrial revolution. Services have been often considered simply as aids to production and have been denied (particulary by marxists but also by liberal economists, both offspring of similar intellectual sources) any acknowledgement of their direct contribution to economic welfare, by assigning non economic added value to many service activities. Even today, for instance, in most countries, the calculation of the national income does not include any value added for the activity of insurance companies except for the salaries they distribute to their staff. When a man has an accident with his car, the compensation he receives has no relevance in terms of added value: it only becomes an added value when the money 
is used to buy another car. The mechanism based on this logic therefore works this way: the more cars or houses are destroyed by accident, the more the national income is increased when and if the compensation is used to buy new cars or build new houses. One should then argue that one of the surest ways of boosting the rate of growth of the national income would be to have some good earthquakes from time to time to stimulate reconstruction. Planning based on present national accounting systems and concepts can be at the root of the most extraordinary ideas, since the notion of welfare is equated with that of added value and/or national income. Things could perhaps be improved a little if a loss could be reckoned as a deducted value, and not just be an occasion to account for every action in terms of added value and in terms of the production system.

At the micro-economic level, the accounting system is not so odd: a loss is normally a loss and not a probable future gain only.

One sees from such examples, that macro-economic theory, overlooking the role of services and reducing the notion of risk to a limited framework, gives the impression of a lighthouse which still produces some glimpses of a territory where a geological change has pushed the sea far away with all the dangers that such a situation implies.

Some type of societal risk management has therefore to come to the rescue of economics which, after all, is one of the most necessary and important of social sciences, in order to restore better navigation in the troubled sea of the world economy. 